\title{
The Effects of Sensorimotor Training Applied to Chronic Low Back Pain Patients on Their Pain and Change in Excitability of Cerebral Cortex Neurons
}

\author{
Sea-Hyun Bae ${ }^{1}$, Jin-Ah Hwang ${ }^{2}$ and Kyung-Yoon Kim ${ }^{2}$ \\ ${ }^{1}$ Department of Physical Therapy Cheongam University, Suncheon, Korea \\ ${ }^{2}$ Department of Physical Therapy Dongshin University, Naju, Korea \\ 'qbseadp@daum.net, ${ }^{2}$ hwangxena@naver.com, ${ }^{2}$ redbead7@daum.net
}

\begin{abstract}
This study aimed to examine the effects of sesorimotor training applied to chronic low back pain patients on their anticipatory postural adjustments (APAs) through changes in movement-related cortical potential (MRCP) and onset time of trunk muscle contraction.

Seven patients whose chronic low back pain sustained for at least six months were selected. In order to present the standard for APAs, a normal group (group I) was selected. The experimental group (group II) consisted of the patients. Low back pain patients conducted exercise 40 minutes per time, four times per week, for four weeks. MRCP was examined through electroencephalography (EEG) in order to look at exercise effect. Changes in readiness potential (RP), motor potential $(M P)$, and movement-monitoring potential $(M M P)$ were measured on six areas of $C_{Z}, C_{3}, C_{4}, F z, F_{3}$, and $F_{4}$. Changes in onset time of muscle contraction were examined through electromyography (EMG).

Together with changes in motor control in the central nervous system, changes in APAs in the trunk muscles (Transversus abdominis muscle (TrA) and external oblique abdominal muscle (EO)) were measured. VAS was used to examine changes in pain.

According to the result of comparing changes in MRCP by sensorimotor training, RP decreased on $C_{Z}, C_{3}, C_{4}, F_{Z}$ and $F_{3}$ and $M P$ decreased on $C_{Z}, C_{3}, C_{4}, F z, F_{3}$, and $F_{4}$ among MRCPs ( $p<0.05)$. In addition, changes in onset time of movement-related muscle contraction were compared and there were significant differences between the TrA and EO with the anterior deltoid muscle $(D A)$ as the reference $(p<0.001)$. VAS that compared changes in pain were significantly different between TrA and EO ( $p<0.05)$.

The above results showed that sensorimotor training had chronic low back pain patients learn muscle control ability, thereby triggering muscle plasticity, and provided a new adaptation environment for the cerebral cortex, thereby improving muscle functions as well as pain.
\end{abstract}

Keywords: Anticipatory Postural Adjustments(APAs), Chronic Low Back Pain, Sensorimotor Training, Movement Related Cortical Potential(MRCP)

\section{Introduction}

Low back pain is a severe problem that affects about $50 \%$ of the population [1]. Ninety percent of acute low back pain is recovered within two months but if low back pain is not treated, it develops into chronic low back pain and triggers functional muscle disorder [2,3]. Usually when the finding of abnormality in the tissues sustains for at lease 12 weeks and pain does not disappear, it is classified as chronic low back 
pain [4]. Such chronic low back pain is a socially crucial problem and resolving it costs much [5].

Movement is a complex process in which the central processing system in the central nervous system integrates and processes information, which induces responses from the musculoskeletal system [6]. APAs are appearance of anticipated responses programmed in the central nervous system 7].

Due to delayed trunk muscle response time chronic low back pain patients experience reduction in cerebral cortex response [8] and postural adjustment capabilities compared to healthy people [9]. In particular, they undergo changes in APAs [10]. Existing exercise methods applied to low back pain patients have concentrated on strengthening their muscles and were not effective in improving muscle recruitment pattern or coordination[11]. Stabilization of the joints is increased by changes in mechanisms such as muscle strength, kinesthetic senses, and muscle tone [12]. Neurological changes were different between healthy people and chronic low back pain patients in the prefrontal cortex, the thalamus, and the orbitofrontal lobe [13]. Chronic low back pain patients' deficit in postural activity transforms the composition of the cerebral motor cortex [8] and triggers functional and morphological changes in the cerebral cortex [14].

It is very important in exercise treatment that it reconditions the proprioceptive senses and improves muscle control ability in chronic low back pain patients. Sensorimotor training is a method to enhance sensory information on abnormal muscles, maximize sensory inputs in different parts of the body, and recover motor control ability [15]. In addition, abnormal posture, base of support, and stimuli are oriented toward the center of gravity through practice [16]. Such training was greatly helpful in improving motor performance and coordination relative to existing training methods [17].

APAs involve supplementary motor area and primary motor area (M1) [18]. Activation of the cerebral cortex from these areas may be measured through MRCPs [19]. MRCPs are to record brain potentials extracted from EEG during voluntary movement tasks [20] and used as research related to pain of chronic low back pain patients [21]. Such MRCPs are composed of three stages: RP, MP, and MMP record highest in between $-600 \mathrm{~ms}$ and $-500 \mathrm{~ms}$, between $-100 \mathrm{~ms}$ and $0 \mathrm{~ms}$, and between $0 \mathrm{~ms}$ and $1 \mathrm{~s}$, respectively[22].

Healthy people's feedfoward is to send an order of motions from the neurological system to the trunk, activating the trunk muscles [10]. However, the time to activate the trunk muscles and activity differ in relation to APAs in chronic low back pain patients [23]. In order to compare differences in muscle control in APAs, EMG is used as a general method to measure onset time of each muscle [24]. The onset time of $\operatorname{TrA}$ contraction is delayed in chronic low back pain patients and therefore motor control of the trunk muscles is insufficient and the trunk muscles are not activated [23]. It is important to examine differences between chronic low back pain patients and healthy people in treating the patients [10].

Accordingly, this study applied sensorimotor training to chronic low back pain patients, identified changes in the movement-related cerebral cortex, and looked at how such changes affected APAs. 


\section{Subjects and Methods}

\subsection{Subjects}

The subjects of this study were seven healthy people and seven chronic low back pain patients. The healthy subjects were those who had not experienced low back pain for the recent six months. The criteria for inclusion as the chronic low back pain patients were: those whose low back pain sustained for at least 12 weeks; those who had no experience of a surgery on the lumbar region due to some orthopedic problem; those whose VAS score ranged from four to six points; those who had no severe deformity or fracture in the spine on the X-ray; those who had no sensory nerve system disorder, vestibular system disorder, neurological or respiratory system disease; those who did not take medication affecting the experiment; and those whose dominant side was the right side. Prior to participation in this study, all the subjects voluntarily consented. Data collection was initiated after approval by the Dongshin University Institutional Review Board was obtained. The characteristics of the subjects are shown in Table 1.

Table 1. Characteristics of Study Participants

\begin{tabular}{ccc}
\hline Parameters & Group I $(\mathrm{n}=7)$ & Group $\Pi(\mathrm{n}=7)$ \\
\hline Age (years) & $31.71 \pm 6.55$ & $35.00 \pm 5.60$ \\
Sex (male/female) & $3 / 4$ & $4 / 3$ \\
Height $(\mathrm{cm})$ & $166.29 \pm 8.70$ & $165.86 \pm 5.90$ \\
Weight $(\mathrm{kg})$ & $66.14 \pm 10.22$ & $67.86 \pm 4.30$ \\
BMI $\left(\mathrm{kg} / \mathrm{m}^{2}\right)$ & $20.38 \pm 5.92$ & $22.69 \pm 3 . .68$ \\
& & $10.75 \pm 5.21$ \\
\hline
\end{tabular}

All data are expressed as means with standard deviation (SD).

\subsection{Methods}

The healthy subjects were assigned to the normal group I and the low back pain patients were allocated to the experimental group II. Sensorimotor training is to activate the trunk muscles and a wobble board was used. This training was to make the ground plane smaller from four points to three points and then to two points; A total of six exercises were designed for balance of the lumbar muscles and effective delivery of fast power [25]. Table 2 displays its specific exercise method. 
Table 2. Sensorimotor Training Program

\begin{tabular}{ll}
\hline Position & Exercise methods \\
\hline Hollowing exercise & $\begin{array}{l}\text { Contract the abdominalmuscles, raising the center of movement } \\
\text { toward the naval in aquadruped position. }\end{array}$
\end{tabular}

Single leg raising in the quadripedal position(Rt/Lt)

Contralateral arm \& leg raising in the quadripedal position (Rt/Lt)

Abdominal bracing

Holding on the bridging position

Single leg raising in the bridging position(Rt/Lt)
Raise one leg and maintain it in aquadruped position and apply the same movement to the opposite leg.

Raise the opposite arm and leg simultaneously in a quadruped position and maintain them; apply the same movement to the opposite side.

Flex the hip and knee joints at $90^{\circ}$ in a supine position; throw out the lower abdomen during inhalation, and contract the lower abdomen during exhalation.

Apply so that the legs do not spreadapart in a bridging position.

Extend one leg in a bridging position, and raise and maintain it. Apply the same movement to the opposite side.

Changes in MRCPs were measured during upper limb flexion using brain waves (QEEG-8; LXE3208, Laxtha Inc, Korea). According to the International 10-20 system[26], the active electrodes were attached to six areas of the cerebral hemisphere $\mathrm{C}_{\mathrm{Z}}, \mathrm{C}_{3}, \mathrm{C}_{4}, \mathrm{~F}_{\mathrm{Z}}, \mathrm{F}_{3}$, and $\mathrm{F}_{4}$ and the ground electrodes and the reference electrodes $\left(\mathrm{A}_{1}\right.$ and $\mathrm{A}_{2}$ ) were attached to the mastoid processes(Figure 1).
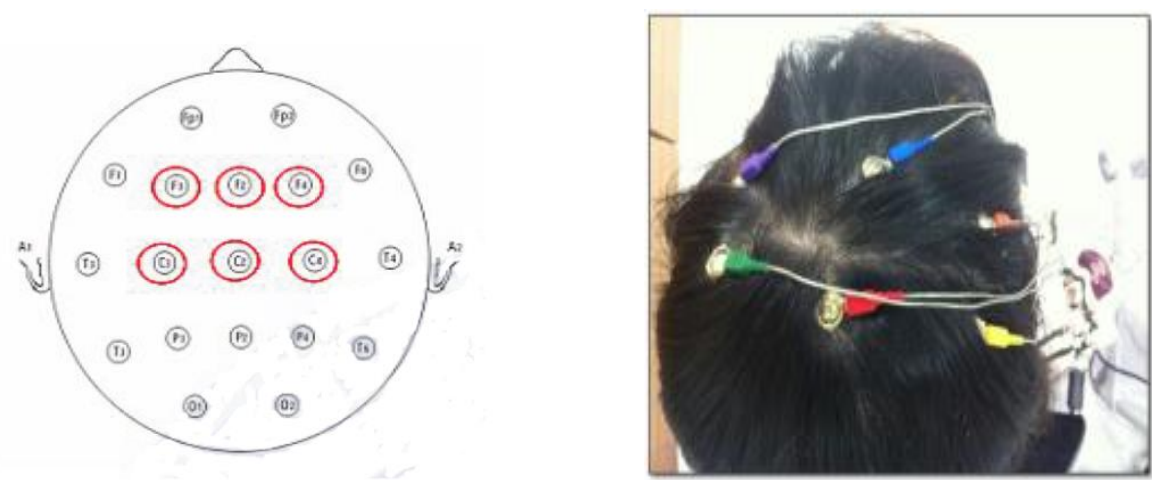

Figure 1. The Illustration of the EEG Electrode Placement $C_{Z}, C_{3}, C_{4}, F_{Z}, F_{3}, F_{4}$ 
The sampling rate for signal collection and the bank pass filter were set at $256 \mathrm{~Hz}$ and 4 to $50 \mathrm{~Hz}$, respectively. In order to minimize skin resistance prior to attachment of the electrodes to the scalp, the scalp surface was washed with alcohol and the electrodes were fixed on the scalp with electrode paste (Elefixz-401CE, Japan). Brain wave signals were collected by flexing the shoulder joint of the non-dominant side by 90 degrees as fast as possible in a standing position. In order to look at changes in activity after the training, RP, MP, and MMP of the MRCP were measured. In order to remove potentials of eye blinking and pupil movement that affect brain waves, a mark was made 2 meters away in front and the subjects stared at the mark. Using EMG (Pocket EMG, BTS co, Italy), onset time of movement related muscle contraction was also measured. The frequency bandwidth for signal collection was set at $20-500 \mathrm{~Hz}$ for analysis. The AgAgcl electrodes were used with the distance between electrodes at $2 \mathrm{~m}$. In order to minimize skin resistance, the hair of the subjects was removed and the skin surface was washed with alcohol. International standardization anatomical and marks EMG position was referred to. The electrodes were attached on the DA, TrA, and EO (Figure 2).

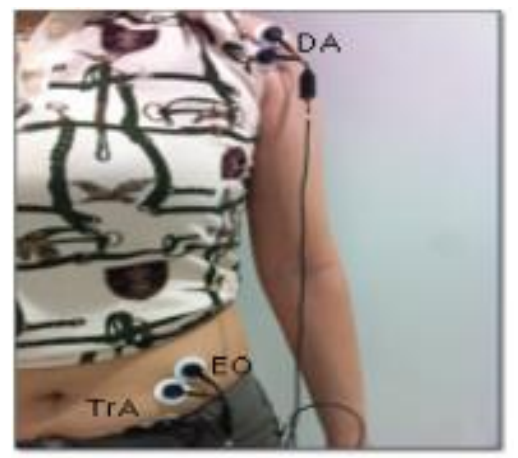

Figure 2. The Changes of Muscle Activites (TrA \& EO)

The measurement method was the same as the EEG. With the DA as the reference point, when contraction of the trunk muscles TrA and EO were initiated first, the value was minus, and when their contraction was initiated later, the value was plus. Each experiment was conducted three times. The subjects took a rest for one minute between measurements (Figure 3).

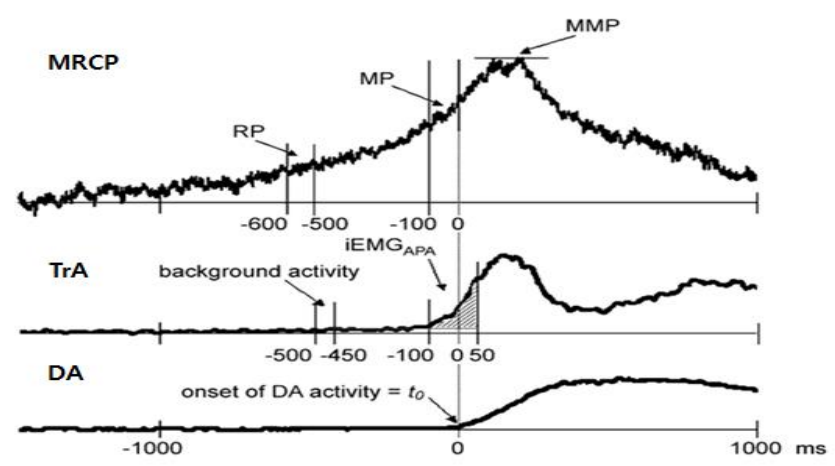

Figure 3. Schematic Representation of the Time Windows used for the Extration of the MRCP Component from EEG Data and of APAs from EMGs 
As a clinical scale to select patients and examine changes in their pain, VAS was used. Its precision was heightened by making the patients mark themselves[32]. Changes in pain may be expressed more sensitively in chronic pain than in acute pain [27].

\subsection{Statistical Analysis}

For statistical analysis, SPSS 18.0 Window version was used. A paired t-test was conducted in order to analyze differences between prior to and after the exercise. Oneway ANOVA was carried out for each group's MRCP and onset time of muscle contraction. A statistical significance level was set at $\alpha=0.05$.

\section{Results}

Changes in the six areas of MRCP $\left(\mathrm{C}_{\mathrm{Z}}, \mathrm{C}_{3}, \mathrm{C}_{4}, \mathrm{~F}_{\mathrm{Z}}, \mathrm{F}_{3}\right.$, and $\left.\mathrm{F}_{4}\right)$ during voluntary upper limb movements prior to and after sensorimotor training were analyzed. There were significant differences in $\mathrm{C}_{\mathrm{Z}}(\mathrm{p}<0.05), \mathrm{C}_{3}(\mathrm{p}<0.05), \mathrm{C}_{4}(\mathrm{p}<0.001), \mathrm{F}_{\mathrm{Z}}(\mathrm{p}<0.001)$, and $\mathrm{F}_{3}(\mathrm{p}<0.001)$ in $R P$, $\mathrm{C}_{\mathrm{Z}}(\mathrm{p}<0.01), \mathrm{C}_{3}(\mathrm{p}<0.001), \mathrm{C}_{4}(\mathrm{p}<0.001)$, and $\mathrm{F}_{4}(\mathrm{p}<0.05)$ in $\mathrm{MP}$, and $\mathrm{C}_{\mathrm{Z}}(\mathrm{p}<0.001), \mathrm{C}_{3}(\mathrm{p}<0.001)$, $\mathrm{C}_{4}(\mathrm{p}<0.05), \mathrm{F}_{\mathrm{Z}}(\mathrm{p}<0.001), \mathrm{F}_{3}(\mathrm{p}<0.001)$, and $\mathrm{F}_{4}(\mathrm{p}<0.001)$ in MMP (Table 3$)$.

Table 3. The Changes of MRCP

\begin{tabular}{|c|c|c|c|c|}
\hline & & \multirow[t]{2}{*}{ Group I } & \multicolumn{2}{|c|}{ Group II } \\
\hline & & & Pre & Post \\
\hline \multirow[t]{8}{*}{$\mathrm{RP}$} & $\mathrm{C}_{\mathrm{Z}}$ & $-2.75 \pm 0.52$ & $-4.34 \pm 2.28$ & $-3.08 \pm 0.38 *$ \\
\hline & $\mathrm{C}_{3}$ & $-2.21 \pm 0.28$ & $-4.04 \pm 1.89$ & $-3.08 \pm 0.48 *$ \\
\hline & $\mathrm{C}_{4}$ & $-1.21 \pm 0.21$ & $-3.46 \pm 0.22$ & $-2.41 \pm 1.11 * * *$ \\
\hline & $\mathrm{F}_{\mathrm{Z}}$ & $-1.95 \pm 0.38$ & $-4.90 \pm 0.40$ & $-3.53 \pm 0.33 * * *$ \\
\hline & $\mathrm{F}_{3}$ & $-1.60 \pm 0.42$ & $-4.69 \pm 0.47$ & $-3.22 \pm 0.32 * * *$ \\
\hline & $\mathrm{F}_{4}$ & $-1.96 \pm 0.29$ & $-4.19 \pm 2.31$ & $-4.15 \pm 7.33$ \\
\hline & $\mathrm{C}_{\mathrm{Z}}$ & $-7.38 \pm 0.58$ & $-12.80 \pm 0.47$ & $-9.55 \pm 4.75^{* *}$ \\
\hline & $\mathrm{C}_{3}$ & $-5.94 \pm 0.48$ & $-10.60 \pm 0.44$ & $-8.77 \pm 0.58 * * *$ \\
\hline \multicolumn{5}{|l|}{ MP } \\
\hline & $\mathrm{C}_{4}$ & $-5.18 \pm 2.33$ & $-9.39 \pm 0.31$ & $-7.50 \pm 0.60 * * *$ \\
\hline & $\mathrm{F}_{\mathrm{Z}}$ & $-4.15 \pm 0.42$ & $-11.44 \pm 5.60$ & $-7.82 \pm 6.00$ \\
\hline
\end{tabular}




$\begin{array}{ccccc} & \mathrm{F}_{3} & -3.26 \pm 0.43 & -9.60 \pm 4.47 & -8.52 \pm 0.72 \\ & & & & \\ & & & & \\ \text { MMP } & & -4.07 \pm 0.48 & -7.13 \pm 7.84 & -6.23 \pm 0.60^{*} \\ & \mathrm{C}_{\mathrm{Z}} & -12.50 \pm 0.82 & -15.57 \pm 0.67 & -12.60 \pm 0.34^{* * * *} \\ & & & \\ \mathrm{C}_{3} & -13.13 \pm 0.58 & -14.90 \pm 0.55 & -13.58 \pm 0.38^{* * *} \\ & & & \\ \mathrm{C}_{4} & -12.64 \pm 0.54 & -15.25 \pm 0.48 & -10.86 \pm 8.24^{*} \\ & & & \\ \mathrm{~F}_{\mathrm{Z}} & -12.45 \pm 0.52 & -16.02 \pm 0.52 & -14.49 \pm 0.50^{* * *} \\ & & & \\ \mathrm{~F}_{3} & -9.32 \pm 0.35 & -15.64 \pm 0.39 & -13.12 \pm 1.25^{* * * *} \\ & \mathrm{~F}_{4} & -11.27 \pm 0.49 & -17.06 \pm 0.70 & -15.17 \pm 0.61^{* * *}\end{array}$

All Values showed mean \pm S.D.

Group I : Normal Group, Group II : Experimental Group

Tested by paired t-test $\left(; p<.05^{* *} p ;<.01^{* * *} p ;<.001\right)$

Changes in onset time of movement-related muscle contraction $\left(\mathrm{C}_{\mathrm{Z}}, \mathrm{C}_{3}, \mathrm{C}_{4}, \mathrm{~F}_{\mathrm{Z}}, \mathrm{F}_{3}\right.$, $\mathrm{F}_{4}$ ) during voluntary upper limb movements prior to and after sensorimotor training were analyzed and there were significant differences in TrA and EO $(\mathrm{p}<0.001)($ Table 4).

Table 4. The Changes of Muscle Activites(TrA \& EO)

\begin{tabular}{llll}
\hline & Group I & \multicolumn{2}{c}{ Group I } \\
& & Pre & Post \\
\hline DA & 0 & 0 & 0 \\
TrA & $-0.75 \pm 3.40$ & $67.64 \pm 6.76$ & $4.90 \pm 5.39^{* * *}$ \\
EO & $32.25 \pm 8.93$ & $81.27 \pm 9.58^{2)}$ & $43.55 \pm 10.58^{* * *}$ \\
\hline
\end{tabular}

All Values showed mean士S.D.

Group I : Normal Group, Group II : Experimental Group

DA : Deltoid Anterior, TrA : Transversus Abdominis, EO : External Oblique

Tested by paired t-test $\left({ }^{*} ; p<.05^{* *} p ;<.01{ }^{* * *} p ;<.001\right)$

VAS, which shows changes in pain after sensorimotor training, was significantly different between prior to and after the training $(\mathrm{p}<0.05)$ (Table 5). 


\section{Table 5. Changes of VAS between in Each Groups}

\begin{tabular}{lll} 
& & Group $\amalg$ \\
& Pre & Post \\
\hline VAS & $5.36 \pm 0.75$ & $3.86 \pm 0.90^{*}$ \\
\hline
\end{tabular}

All Values showed mean \pm S.D

\section{Discussion}

APAs trigger postural adjustments of the body in advance based on previous experiences [28]. In addition, learning makes movements memorized in the central nervous system and enables postural adjustments for movements [9]. However, when APAs are delayed, appropriate coordination and neural transmission in pain change [29]. In chronic low back pain patients, APAs occur late due to weakened upper limb, lower limb, and trunk muscles when they move [30]. They also have errors in making a posture again [31].

Lumbar exercise program is used much in the clinical field as a treatment method for chronic low back pain patients. Accordingly, this study had chronic low back pain patients carry out sensorimotor training. How voluntary upper extremity movements affected APAs was examined by looking at changes in MRCP and onset time of trunk muscle contraction. In addition, VAS was employed for clinical evaluation.

MRCP is brain potential recorded on the scalp when voluntary movement occurs [32]. Research that used EEG on patients with chronic musculoskeletal system pain reported that there were functional changes in the brain and such changes were helpful in managing chronic pain [33]. Cz area is related to the primary motor cortex (M1) and takes charges of the hands mostly [34]. $\mathrm{C}_{3}$ and $\mathrm{C}_{4}$ are associated with the premotor cortex and play an important role in the stage of practicing movements. [35]. $\mathrm{F}_{\mathrm{Z}} \mathrm{F}_{3}$, and $\mathrm{F}_{4}$ areas are related to the frontal lobe and concern planning, practicing, and evaluating behaviors and goal-directed motions[36]. MCRPs appear when voluntary movements activate the cerebral cortex and represent movement training responses while preparing and practicing movements [37]. RP includes auxiliary motor area and represents activity of the cerebral cortex while preparing movements [34]. MP occurs in the centrosphere related to the primary motor area [38]. Movements are planned and practiced; they are initiated before motions starts [39]. MMP inputs afferent senses in the peripheral [38] and movements occur finally in the spinal nerve [40].

This study examined changes in MRCP in the $\mathrm{C}_{\mathrm{Z}}, \mathrm{C}_{3}, \mathrm{C}_{4}, \mathrm{~F}_{\mathrm{Z}}, \mathrm{F}_{3}$, and $\mathrm{F}_{4}$ areas by applying sensorimotor training. In MRCP, RP, MP, and MMP saw significant changes in the $\mathrm{C}_{\mathrm{Z}}, \mathrm{C}_{3}, \mathrm{C}_{4}, \mathrm{~F}_{\mathrm{Z}}, \mathrm{F}_{3}$ areas, $\mathrm{C}_{\mathrm{Z}}, \mathrm{C}_{3}, \mathrm{C}_{4}, \mathrm{~F}_{4}$ areas, and $\mathrm{C}_{\mathrm{Z}}, \mathrm{C}_{3}, \mathrm{C}_{4}, \mathrm{~F}_{\mathrm{Z}}, \mathrm{F}_{3}$, and $\mathrm{F}_{4}$ areas, respectively. There was movement-related cerebral cortex activity in the primary motor area $\left(\mathrm{C}_{\mathrm{Z}}\right)$, premotor area $\left(\mathrm{C}_{3}\right.$ and $\left.\mathrm{C}_{4}\right)$, and prefrontal area $\left(\mathrm{F}_{\mathrm{Z}}, \mathrm{F}_{3}\right.$, and $\left.\mathrm{F}_{4}\right)$. MRCP when movements occurred were low in chronic low back pain patients. APAs were able to appear in chronic low back pain patients by increased activity of the cerebral cortex like healthy people. The parts that plan, practice, and evaluate movements played an important role in MRCP. After training for a short time period, amplitude of cerebral cortex neuron activation was low [37]. This means that increased brain activation during voluntary movements leads to rise in APAs. 
Changes in trunk muscles occur in chronic back pain patients [9], and recently there has been a lot of interest in such changes [41]. Improvement in response speed by training trunk muscles recover muscle athropy, relieving and even preventing pain [42]. In addition, enhancement of muscular activity during movements triggers effective movements [23]. EMG has been used for neurological insight into human behaviors [43]. Regarding onset time of muscle contraction, the order of onset time of specific muscles was calculated by measuring the time taken to reach the threshold of each muscle [44]. The onset time unit of muscle contraction consists of premotor reaction time, a stage prior to muscle contraction, and motor reaction time, a stage when muscle contraction occurs by actual movements [45].

This study examined changes in APAs in trunk muscles (the transversus abdominis muscle, TrA, external oblique abominal muscle, and EO). Onset time of movementrelated muscle contraction statistically significantly differed in the $\operatorname{TrA}$ and EO between prior to and after the experiment. This means that trunk muscles of chronic low back pain patients were delayed but their response time improved close to healthy people after sensorimotor training. TrA response time was shorter in healthy people than chronic low back pain patients during upper limb movements [46]. While the $\operatorname{TrA}$ moves faster than the DA in healthy people, TrA was delayed three times as late as the DA in chronic low back pain patients [47]. Response time of the EO became shorter after motor control of chronic low back pain patients [48]. Because trunk muscles of chronic low back pain patients were not activated, their response time was considerably delayed [47]. This shows that trunk muscles contribute to stability of balancing the body and the trunk maintains a stable posture against external stimuli. Further, onset time of muscle contraction of chronic low back pain patients became shorter after sensorimotor training; their trunk muscles grew strengthened.

In the present study, VAS, which measures changes in pain, significantly changed after sensorimotor training. Such result is considered to show that sensorimotor training reduces pain. According to VAS evaluation result, sensorimotor training played an important role in controlling pain [49].

The present study result signified that sensorimotor training increased intermuscular adjustments, improving responses to sensory information [16]. Sensorimotor training was found to be conducive to enhancing postural adjustments of athletes, children, adults, and elderly people as well as patients [50]. Resultantly, sensorimotor training had APA effects in chronic low back pain patients' MRCP and muscle activity responses.

Chronic low back pain affects muscle functions that plan and practice movements of the cerebral cortex apart from pain. Sensorimotor training changes cerebral cortex activity and onset time of muscle contraction, providing APAs and thereby improving pain and muscle functions.

\section{References}

[1] R. A. Deyo, S. K. Mirza and B. I. Martin, "Spine, Back Pain Prevalence and Visit Rates", (2006)

[2] K.S. Park, E. N. Ryoo and M. H. Choi. J Korean Acad Adult Nurs, vol. 17, (2005), p. 77.

[3] B. D. Doctoral, Disseration, University of Miami, USA (2005)

[4] H. Merskey and N. Bogduk. IASP Task Force on Taxonomy, vol. 2, (1994), p. 209.

[5] G. Roche, A. Ponthieux, E. Parot-Shinkel, N. Jousset, L. Bontoux and V. Dubus, "Arch Phys Med Rehabil" vol. 88, (2007), pp. 1229.

[6] L. M. Nashner, "Sensory", Nashville, TN, 5, (1989).

[7] J. Massion. Prog Neurobiol, vol. 38, no. 35, (1992). 
[8] J. V. Jacobs, S. M. Henry and K. J. Nagle, Clinical Neurophysiology, vol. 121, (2010), pp. 431.

[9] A. Radebold, J. Cholewicki, G. K. Polzhofer and H. S. Greene. Spine, vol. 26, (2001), pp. 724.

[10] P. W. Hodges and C. A. Richardson. Arch Phys Med Rehabil, vol. 80, (1999), pp. 1005.

[11] E. H. Yun. Seoul, Dankook University, Unpublished master's thesis, (2003).

[12] V. Janda and M. VaVrova, Rehabilitation of the Spine, (1996), pp. 319.

[13] I. D. Grachev, B. E. Fredickson and A. V. Apkarian. Pain, vol. 89, no. 7. (2000).

[14] J. H. Benedict, L. Marston and L. H. De Souza. Spine, Pubmed (2009).

[15] E. Kapreli, S. Athanasopoulos, M. Papathanasiou, P. D. Van Hecke Keleki, R. Peeters, N. Strimpakos and S. Sunaert. Cortex, vol. 43, no. 219, (2007).

[16] F. Amal and Ahmed. Journal of Advanced Research, vol. 2, (2011), pp. 305.

[17] W. Taube, M. Gruber, S. Beck, M. Faist, A. Gollhofer and M. Schubert. Acta Physiol(Oxf), vol. 189, (2007), pp. 347.

[18] F. Viallet, J. Massion, R. Massarino and R. Khalil. Exp, Brain Res, vol. 88, (1992), pp.674.

[19] A. Ikeda, H. O. Lüders, R. C. Burgess and H. Shibasaki. rain, vol. 115, (1992), pp. 1017.

[20] V. Siemionow, G. H. Yue, V. K. Ranganathan, J. Z. Liu and V. Sahgal. Exp Brain Res, vol. 133, (2000), pp. 303.

[21] H. Flor. J Rehabil Med, vol. 41, pp. 66, (2003).

[22] S. Yoshida, K. Nakazawa, E. Shimizu and I. Shimoyama. Gait Posture, vol. 27, (2008), pp. 97.

[23] H. Tsao and P. W. Hodges. J Electromyogr Kinesiol, vol. 18, (2008), pp. 559.

[24] G. Staude and W. Wolf. Med Eng Phys, vol. 21, (1999), pp. 449.

[25] G. Ronald, D. C. Rogers and C. S. C. S. "Ocean Shores”, Strength and Conditioning Journal, vol. 2, no. 30 (2006).

[26] H. Jasper. EEG and Clynical Neurophysiology, vol. 10, pp. 371, (1958).

[27] C. H. Jeon, D. J. Kim, D. J. Kim, H. M. Lee and H. J. Park. J of Korea Spine Surg, vol. 12, (2005), pp. 146.

[28] A. Shumway-Cook, M. H. Woollacott. Baltimore, Md, Lippincott Williams , Wilkins (1995).

[29] G. L. Moseley and P. W. Hodges. Clin J Pain, vol. 21, (2005), pp. 323.

[30] N. Kanekar, M. J. Santos and A. S. Aruin. "Clinical Neurophysiol”, vol. 119, (2008), pp. 2304.

[31] K. L. Newcomer, E. R. Laskowski, B. Yu and J. C. Johnson, An K.N. Spine, vol. 25, (2000), pp. 2488.

[32] A. Ikeda and H. Shibasaki. J Clin Neurophysiol, vol. 9, (1992), pp. 509.

[33] A. V. Apkarian, M. N. Baliki and P. Y. Geha. Prog Neurobiol, vol. 87, (2009), pp. 81.

[34] M. T. Banich. Cognitive Neuroscience and Neuropsychology( $2^{\text {nd }}$ ed). Boston, Houghton Mifflin, (2004)

[35] R. Q. Cui, D. Huter, W. Lang and L. Deecke. NeuroImage, vol. 9, (1999), pp. 124.

[36] B. C. Jobst and P. D. Williamson. Psychiatric Clinics of North America, vol. 28, (2005), pp. 635651.

[37] A. L. Smith and W. R. Staines. Brain Research, vol. 1071, (2006), pp. 165.

[38] K. Toma, M. Hallett. In M. Jahanshahi and M. Hallett. Kluwer Academic,Plenum, vol. 113, (2003).

[39] Y. Fang, V. Siemionow, V. Sahgal, F. Xiong and G. H. Yue. Brain Res, vol. 1023, (2004), pp. 200.

[40] A. Ikeda, H. Shibasaki. In M. Jahanshahi and M. Hallett, "The Bereitschaftspotential, Movement-Related Cortical Potentials", Kluwer Academic Plenum Publishers, (2003) pp. 45-59.

[41] C. M. Swart, J. F. Stins and P. J. Beek. European Journal of Pain, vol. 13, (2009), pp. 902.

[42] S. Luoto, H. Aalto, S. Taimela, H. Hurri, I. Pyykko and H. Alaranta. Spine, vol. 23, (1998), pp. 2081.

[43] A. N. Lay, C. J. Hass, T.R. Nichols and R. J. Gregor, Journal of Biomechanics, vol. 40, (2007), pp. 1276.

[44] A. S. Lee, J. Cholewicki and N. P. Reeves. Journal of Biomechcs, vol. 40, (2007), pp. 3521.

[45] R. A. Schmidt and T. D. Lee. "Motor control and learning a behavioral emphasis, 3rd Edition", Human Kinetics, Champaign IL, (1999).

[46] S. H. Bae, J. A. Hwang and K. Y. Kim, Advanced science and technology letters(ASTL), vol. 47, (2014).

[47] D. A. Neumann. Kinesiology of the Musculoskeletal System. Jungdammedial, (2004). 
[48] D. M. Urquhart, P. W. Hodges, T. J. Allen and I. H. Man Ther, vol. 10, no. 144, (2005).

[49] J. A. Verbunt, H. A. Seelen, J. W. Vlaeyen, G. J. van de Heijden, P. H. Heuts, K. Pons, J. A. Knottnerus. Eur J Pain, vol. 7, no. 9, (2003).

[50] G. D. Myer, K. R. Ford, J. L. Brent, T. E. Hewett. J Strength Cond Res, vol. 20, (2006), pp. 345.

\section{Authors}

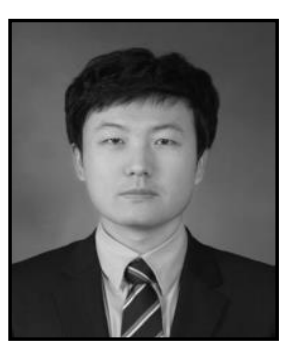

\section{Sea-Hyun Bae}

February 2011: Dept.of Physical Therapy, Dongshin University (M.S.)

February 2014: Dept.of Physical Therapy, Dongshin University (Ph.D.)

March 2013 Current: Dept of Physical Therapy, Cheongam College

(Visiting Professor)

<Interests>: Neurological physical therapy, Clinical electrophysiological

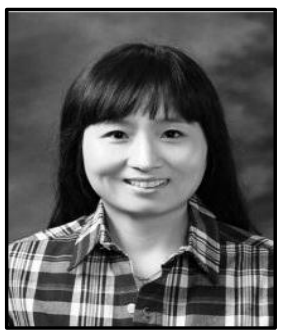

\section{Jin-Ah Hwang}

February 2013: Dept.of Physical Therapy, Dongshin University (M.S.)

March 2013 Current: Dept.of Physical Therapy, Dongshin University (Ph.D.)

<Interests>: Musculoskeletal physical therapy, Therapeutics exercise

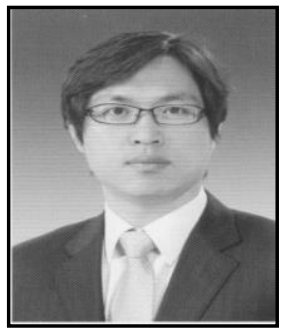

\section{Kyun-Yoon Kim}

February 2004: Dept.of Physical Therapy, Dongshin University (M.S.)

February 2007: Dept.of Physical Therapy, Dongshin University (Ph.D.)

March 2006 Current: Dept of Physical Therapy, Dongshin University

(Professor)

<Interests>: Neuroscience, Neurological physical therapy 
International Journal of Bio-Science and Bio-Technology Vol.6, No.4 (2014) 